\title{
Article \\ Circularity for Electric and Electronic Equipment (EEE), the Edge and Distributed Ledger (Edge\&DL) Model
}

\author{
Terje Andersen * $*$ and Bjørn Jæger (1) \\ Faculty of Logistics, Molde University College, Specialized University in Logistics, P.O. Box 2110, \\ NO-6402 Molde, Norway; Bjorn.Jager@himolde.no \\ * Correspondence: Terje.Andersen@himolde.no; Tel.: +47-711-95-752
}

Citation: Andersen, T.; Jæger, B. Circularity for Electric and Electronic Equipment (EEE), the Edge and Distributed Ledger (Edge\&DL) Model. Sustainability 2021, 13, 9924. https://doi.org/10.3390/su13179924

Academic Editors: Gianmarco Bressanelli, Federico Adrodegari, Daniela Cristina Antelmi Pigosso and Vinit Prida

Received: 28 July 2021

Accepted: 30 August 2021

Published: 3 September 2021

Publisher's Note: MDPI stays neutral with regard to jurisdictional claims in published maps and institutional affiliations.

Copyright: (c) 2021 by the authors. Licensee MDPI, Basel, Switzerland. This article is an open access article distributed under the terms and conditions of the Creative Commons Attribution (CC BY) license (https:// creativecommons.org/licenses/by/ $4.0 /)$.

\begin{abstract}
In the transition to a circular focus on electric and electronic products, manufacturers play a key role as the originators of both the products and the information about the products. While the waste electric and electronic equipment (WEEE) directive's contemporary focus is on handling the product as waste after its end of life, the circular economy focuses on retaining the product's value with a restorative system. The polluter-pays principle requires producers of pollution to bear the costs of handling the pollution, leading to the extended producer responsibility (EPR) principle. This requires manufacturers to change their focus from their current passive role of out-sourcing end-oflife treatment to taking explicit responsibility for product management over an extended period of time. This paper investigates how a manufacturer can assume its responsibility to achieve circularity for its products. Based on our findings, three fundamental circularity principles, the circular electric and electronic equipment (CEEE) principles, for manufactures of electronic and electrical equipment are defined: (1) Serialize product identifiers, (2) data controlled by their authoritative source at the edge, and (3) independent actors' access to edge data via a distributer ledger are the foundation of the Edge and Distributed Ledger (Edge\&DL) model. We demonstrate the model through a case study of how to achieve circularity for lighting equipment. The CEEE principles and the demonstrated model contribute to building new circularity systems for electronic and electric products that let manufacturers undertake their extended product responsibility.
\end{abstract}

Keywords: circularity; circular supply chains; distributed ledger; edge computing; e-waste; WEEE; case study

\section{Introduction}

More than 30 years ago, the term "sustainable development" was introduced in the UN report "Our Common Future" [1]. Sustainable development not only focuses on economic development, but also environmental and social dimensions [2]. One overall strategy to achieve more sustainable development is to move from a traditional linear business model, characterized by a take-make-use-dispose approach, to a circular economy (CE) model, in which materials and energy remain in a restorative system $[3,4]$. Electric and electronic waste (e-waste) is one of the world's fastest growing waste streams [5,6]. The end-of-life equipment as waste include valuable materials, such as gold, cobalt, copper, and phosphor. The value of this waste is estimated at approximately \$57 billion USD [6]. Several studies have identified research gaps within e-waste. It has been a call for research on product management by Islam et al. [7] who called for product specific network models that consider more product-oriented case studies, as well as more studies on the circular economy in developing infrastructures for sustainable activities. They also highlight the minimal focus on reuse and repair within e-waste research. Closely related to product management is the role of the manufacturer of the products. A call for research on how manufacturers should adapt has been forwarded by Bressanelli et al. who performed a systematic literature review on $\mathrm{CE}$ in the e-waste industry. They proposed 10 different research agendas, 
including focusing on how $\mathrm{CE}$ changes company behavior, and focusing more on the regenerative $R s$ in the $4 \mathrm{R}$ strategies i.e., reduce, reuse, remanufacture and less on the recycle strategy that is part of waste handling [8]. Likewise, Andersen argued for further studies on how digitalization of the EEE supply chain can affect the reverse supply chain (RSC) to improve circularity in the EEE industry from a manufacturer's perspective [9], especially how digital technology can link the production of EEE to handling the product at its end of life. On a more general $\mathrm{CE}$ level, Zeiss et al. argue for the usage of information systems (IS) to improve circularity [10]. Diedler et al. compared WEEE treatment in Serbia and Germany addressing data quality and stated that quality data remains a concern for transparency and reporting. Their recommendations include a more comprehensive and specially designed data tracking system with detailed information on WEEE flows during all stages and the development of an open-access online platform where all WEEE related data are transparently visible [11].

Summing up, the move towards circularity calls for research on meeting the manufacturer's challenges, managing its products, and developing supportive infrastructures for its extended partner network. This study aims to contribute to answer these calls by investigating the following research question: How can an EEE manufacturer take on its extended producer responsibility to achieve circularity for EEE?

The organization of the rest of the paper is as follows. In Section 2, we present background information on e-waste, the transition from the waste perspective to the circular perspective, and product life phase information. In Section 3, we briefly describe the methodology used in the study, before introducing the three fundamental circular principles in Section 4. In Section 5, we introduce a conceptual model for product information handling based on edge computing principles and distributed ledger (DL) technology. Section 6 holds the discussion part before we conclude our work, including limitations and further research in Section 7.

\section{Background}

There is an increased focus on sustainability both from the research community and society at large. Sustainability is a joint emphasis on environmental protection, economic, and social dimensions, known as the triple bottom line [2]. Within logistics, the supply chain management (SCM) has their sustainable supply chain management (SSCM) focusing not only on the economic, but also the environmental and social part of supply chains. While green supply chain management (GSCM) covers the environmental part of SSCM [12], there are arguments that the social part of SSCM is under-researched in science [13]. Our research is on the need to move from the current e-waste handling to more sustainable solutions, an area of economic importance due to valuable and precious materials as well as a need for cost efficient global logistical operations. The environmental impact of e-waste materials may have severe environmental consequences, as well as a social impact since much of the e-waste are exported to countries in the global south, resulting in air, soil, and water pollution [14]. By this, it is seen that corporate-social responsibility (CSR) is closely linked with extended producers' responsibility (EPR). The sustainability focus involves a transition from a linear take-make-use-dispose model to a CE model where the material is handled primarily by processes such as maintenance, repair, reusing, refurbishing, and remanufacturing [3]. The circularity focus can be seen as the fourth dimension, including a time dimension, securing the protection of further generations for economic, environmental, and social concerns [15].

\subsection{Circularity and Linearity: System vs. Product Perspecitves}

Circular models are proposed by researchers and organizations with some variations in the granularity of actions performed to obtain a restorative system. To illustrate, two common models are (a) the CE model by the United Nation International Resource Panel [16] and the butterfly model by the Ellen MacArthur Foundation [17] with materials on the right butterfly wing. Both models describe $\mathrm{CE}$ processes including in-use, maintenance 
and repair, reuse, refurbishment, remanufacturing, and disposal. These are general circular economy system models rooted in a "cradle to cradle" model, as described by Braungart et al., (2012), which is a holistic model that seeks to create systems that are waste-free [18]. The system models involve many actors, actions, and processes.

For a manufacturer that seeks to implement its extended producer requirement in practice, the system model serves are too general to guide operational actions. For this, a model that focus on the core object in question, i.e., the product, is needed.

Interestingly, from a product perspective, life is not circular but linear in the time dimension. Any product will eventually reach a point at which it no longer qualifies for maintenance, reuse, repair, or refurbishment-either because of the associated cost, or because its quality and utility potential have been degraded due to tear and wear. At that point, called the End-of-Life (EoL) point in Figure 1, remanufacturing or recycling are the preferred CE EoL-actions. The Middle-of-Life (MoL) actions are maintenance, repair, reusing, refurbishing, and remanufacturing. The actions are described in Table 1 and illustrated in Figure 2. The timeline is sequential (time-linear) as seen from the product with overlap or circle. Note that extending the MoL period by repeating the MoL actions over time is a CE goal. Circularity is obtained at the system level by a regenerative system that reuses components of products after their EoL. For the EoL actions, remanufacturing and recycling the product consists of the product being disassembled into its parts, with each part being processed to make it ready for use in another product as illustrated by Product $C$ in Figure 3. To recover the value of the parts, there is a need for cost-efficient remanufacturing and recycling systems [19].

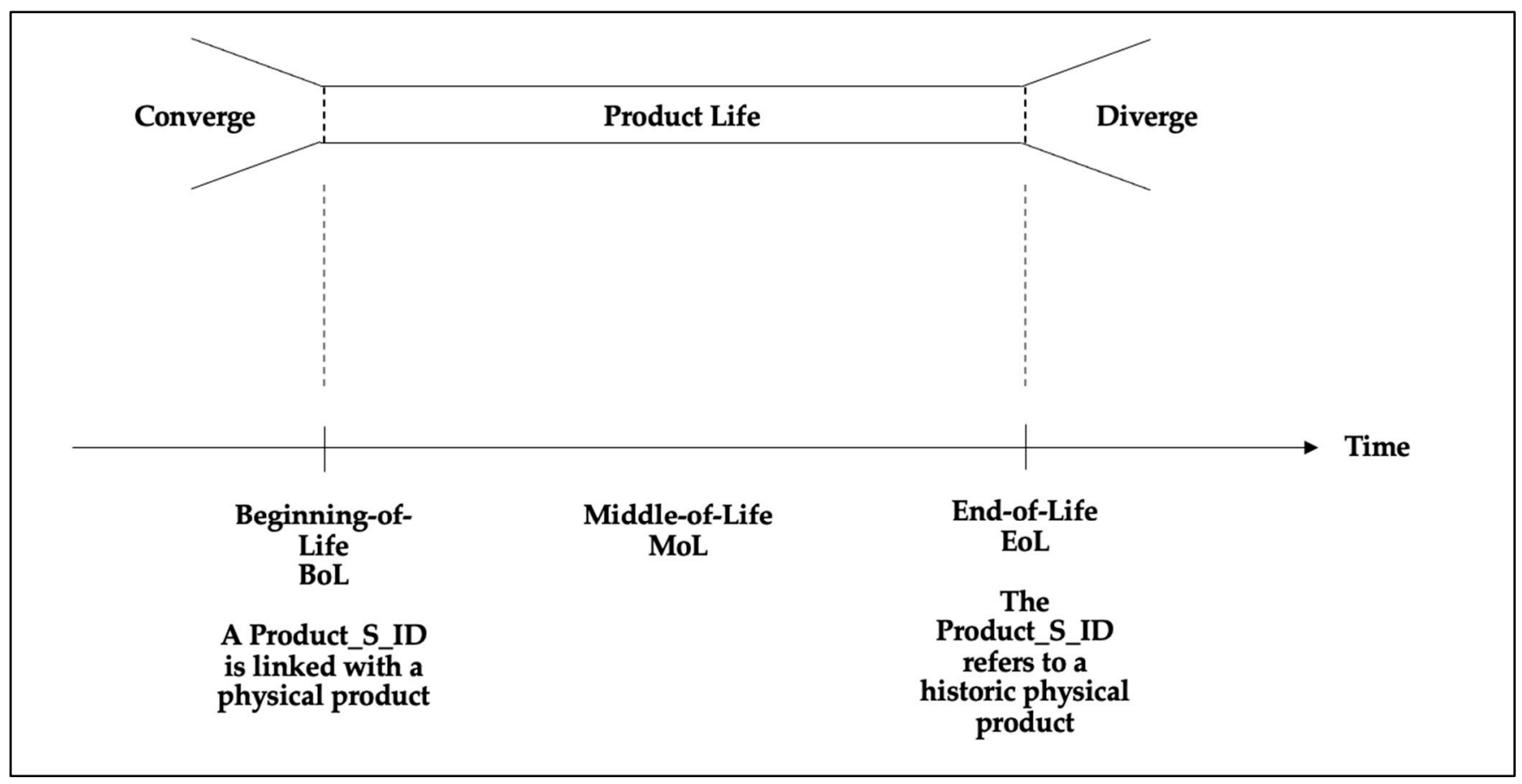

Figure 1. The linear product life perspective with time running from left to right covering the sequential phases $\mathrm{BoL}, \mathrm{MoL}$ and EoL. Parts converge into a product on the left at BoL and diverge into parts again after EoL at the right. 
Table 1. MoL- and EoL-circularity actions are displayed in the upper portion and waste-actions are presented in the lower portion.

\begin{tabular}{|c|c|c|c|}
\hline Action & Description & $\begin{array}{l}\text { Dis-Assembly } \\
\text { Required }\end{array}$ & $\begin{array}{l}\text { Action Type (MoL, } \\
\text { EoL, Waste) }\end{array}$ \\
\hline Maintenance & $\begin{array}{c}\text { Activities to keep an e-product in the desired operating } \\
\text { condition }[20,21]\end{array}$ & No & MoL \\
\hline Reuse & $\begin{array}{l}\text { Use the e-product again for the same purpose as when it } \\
\text { was manufactured [16] }\end{array}$ & No & MoL \\
\hline Repair & $\begin{array}{l}\text { Fix a fault or replace defective components to make it } \\
\text { fully functional as when it was manufactured [16] }\end{array}$ & No & MoL \\
\hline Refurbish & $\begin{array}{c}\text { Modification to make it fully functional as when it was } \\
\text { manufactured [16] }\end{array}$ & No & MoL \\
\hline Remanufacture & $\begin{array}{c}\text { Industrial process to transform e-products or their parts } \\
\text { into products that are as functional as original } \\
\text { manufactured products }[16,22]\end{array}$ & Yes & EoL \\
\hline Recycle & $\begin{array}{c}\text { Operations for reprocessing products, not necessarily for } \\
\text { the original purpose }[17,18]\end{array}$ & Yes & EoL \\
\hline Collect waste & PROs collect e-waste after EoL $[17,18]$ & No & Waste \\
\hline Recovery of energy & Burning and using the heat $[17,18]$ & No & Waste \\
\hline Placement in landfill & Transport and digging $[17,18]$ & No & Waste \\
\hline
\end{tabular}

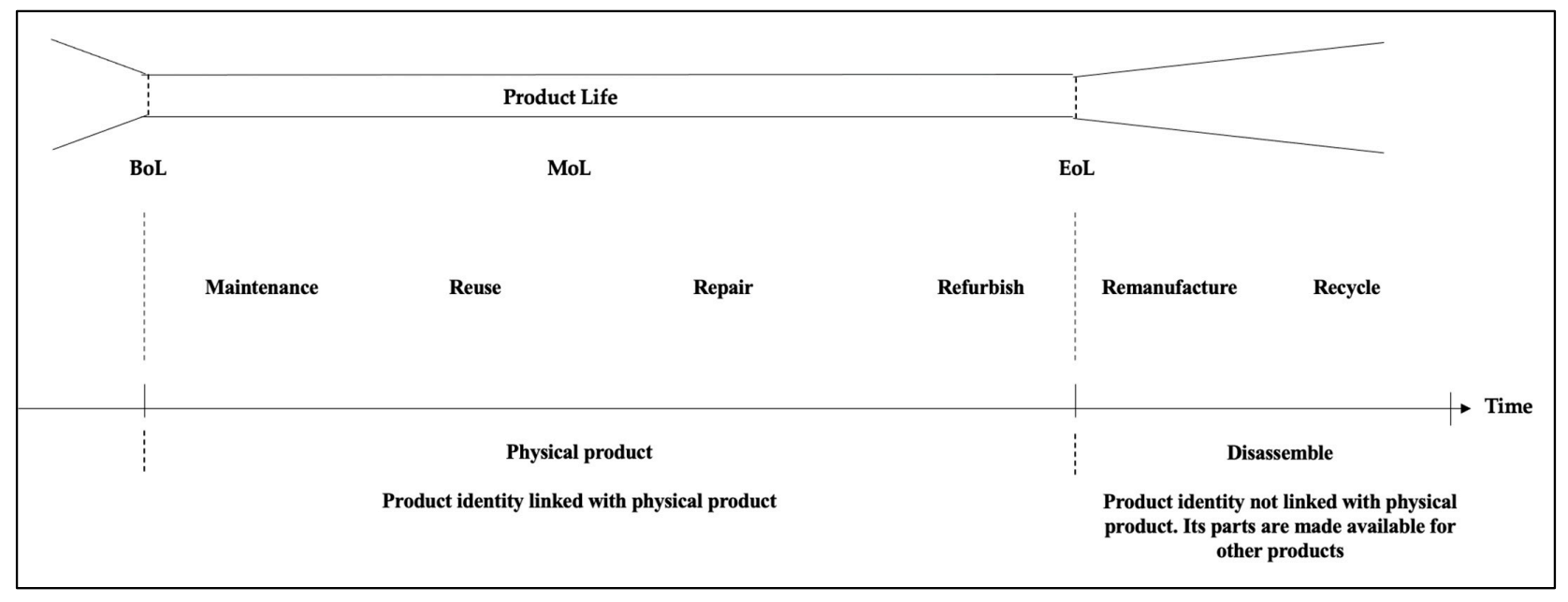

Figure 2. Product life related to the during-life circularity actions Maintenance, Reuse, Repair, and Refurbish. After EoL, the circularity actions are Remanufacture and Recycle.

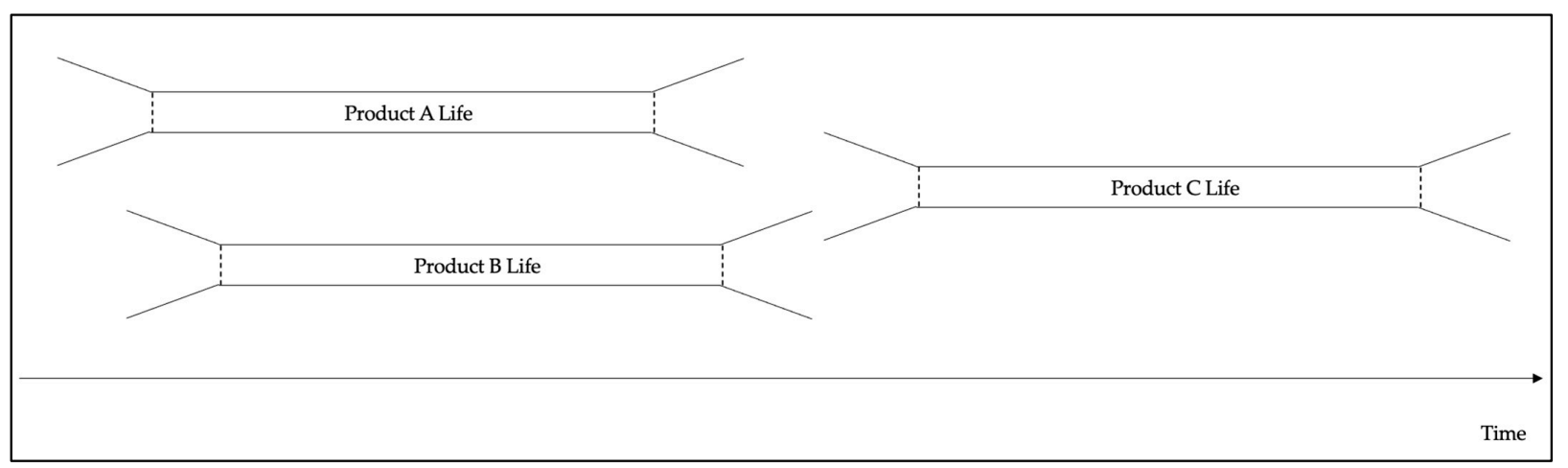

Figure 3. Products A and B are disassembled after their EoL, with some parts used as parts in Product C. Remaining parts of $\mathrm{A}$ and $\mathrm{B}$ are used in other products (not illustrated). 
In addition, the unwanted waste activities are still until the ideal of circularity is reached. These are collecting waste, the recovery of energy, and placement in landfill (lower part of Table 1).

\subsection{Circularity vs. Waste}

Circular economy (CE) promotes the transition from a linear economic model characterized as a take-make-use-dispose model, to a more circular, closed-loop economic model where the material flows through processes such as maintenance, repair, reuse, refurbishment, remanufacture, and recycle [3]. Geissdoerfer et al. [4] define CE "as a regenerative system in which resource input and waste, emission, and energy leakage are minimized by slowing, closing, and narrowing material and energy loops. This can be achieved through long-lasting design, maintenance, repair, reuse, remanufacturing, refurbishing, and recycling". Different levels of circularity are related to how well they may function, both regarding the amount of energy consumed and the amount of basic elements (raw materials) used, from a pure waste perspective (low level) to an ideal situation where all resources are reintroduced in the economy without extra resources or waste (high level) [23]. The European Union (EU) supports the transition to a more circular economy, both from an environmental perspective (i.e., waste management and reduction of landfill) as well as from an economic perspective such as innovation and job creation [24]. Waste handling has a long history in science and in daily life. Waste hierarchies (e.g., 4Rs, 5Rs) also have a long history. The EU waste hierarchy [25] divides waste into four categories: Disposal, recovery, recycling, and preparation for re-use. A fifth level, prevention, is included to stage the final goal. Potting et al. [23] used a 10R approach and linked the Rs to different circular strategies. In Figure 4, CE strategies, WEEE treatment according to the European WEEE directive, and the EU waste hierarchy are presented. The blue portion represents the waste hierarchy, the green is the circular strategies, and the red is the WEEE directive. As illustrated, the WEEE directive focuses on the lower sections of the waste hierarchy and circular strategies. Several studies have observed this $[9,26]$. One important prerequisite to improve this situation, going from waste to circularity, is to have a well-functioning information flow within the forward and reverse supply chains [27].

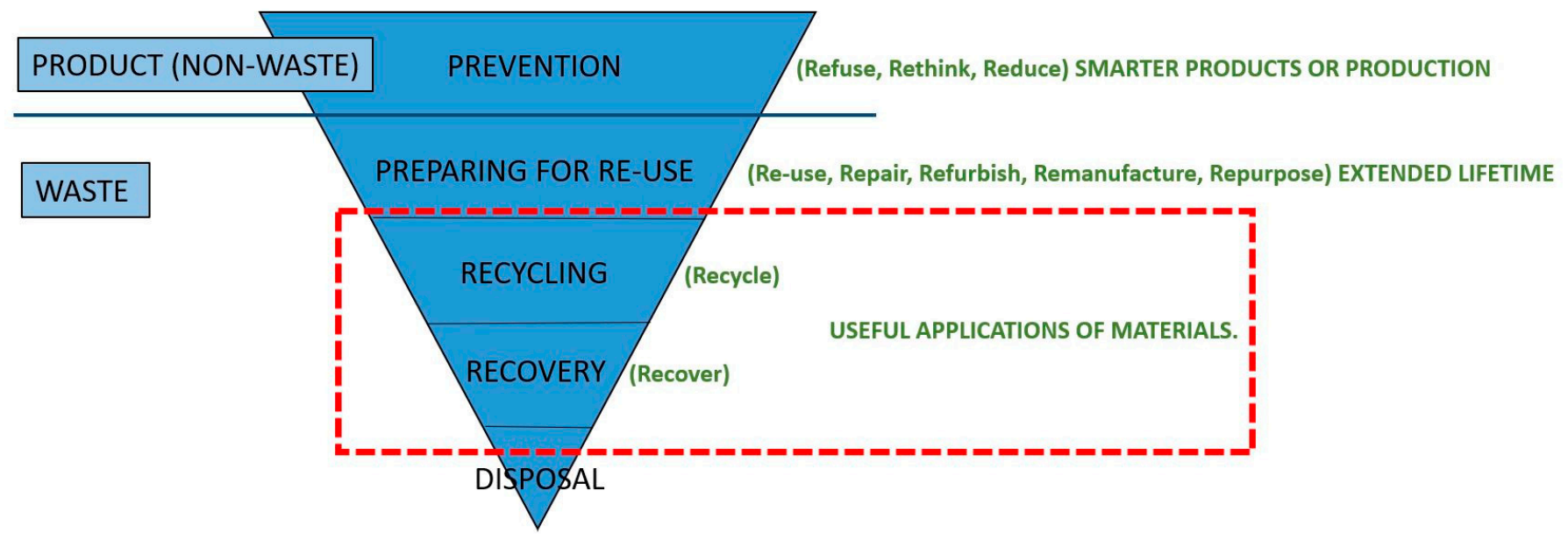

Figure 4. EU waste hierarchy (blue), circular strategies (green), and the EU WEEE directive (red). From [9].

\subsection{Contemporary Handling of e-Waste by the WEEE Directive}

The amount of e-waste is increasing because people use more electrical and electronic equipment (EEE) [13]. In addition, e-waste often contains hazardous materials [28] as well as some important raw materials like cobalt, copper, and phosphor. Practitioners and researchers have an increased interest in how to recover valuable raw materials from the landfill or other disposal areas by landfill mining [29]. Many aspects within e-waste/WEEE 
have been studied. In 2019, Zhang, L., et al. [30] identified 2847 publications within the area, most within the field of environmental science. However, the E-waste/WEEE studies have been criticized for overfocusing on metal recycling and recovery [31]. Switching focus to WEEE management, an international approach and interdisciplinary research was addressed. European countries have been covered by the European WEEE legislation for nearly 20 years [32,33]. This legislation is based on two overall principles. One EPR states that producers must take responsibility for the EoL phase of the products they make [34]. The other, the polluter-pays principle, states that the one responsible for the waste must pay the cost of appropriately handling the waste. Over the years, WEEE has been divided into different categories. Presently, the directive has six different categories, presented in Table 2. Furthermore, for e-waste handling in Europe, the producers can outsource their EPR to a producer responsibility organization (PRO), which collects and handles the e-waste after EoL [35,36].

Table 2. Categories of EEE covered by the WEEE directive. From [33].

\begin{tabular}{cc}
\hline$\#$ & Category \\
\hline 1 & Temperature exchange equipment \\
3 & Screens, monitors, and equipment containing screens having a surface greater than $100 \mathrm{~cm}^{2}$ \\
4 & Lamps \\
5 & Small equipment (no external dimension more than $50 \mathrm{~cm}$ ) \\
6 & Small IT and telecommunication equipment (no external dimension more than $50 \mathrm{~cm})$ \\
\hline
\end{tabular}

\section{4. e-Product Information}

For supply chains, information flow is one of three important flows, together with material and financial flows [37]. The information flow is crucial to the performance of a reverse supply chain, but the development of standards and protocols has not reached the same level as forward supply chains [38,39]. The information related to a product's life phases is divided into different categories depending on the state of the product in a life phase, like product lifecycle management (PLM) during its life, product development (PD) pre-product-life, manufacturing/production, in the use phase, maintenance, and the EoL phase [40]. Kurilova-Palisaitiene et al. [41] identified nearly 30 types of product lifephase information for remanufacturing. The information was represented orally, on paper or digitally, and many types were not publicly available. Lack of product information availability for circularity actors may slow down the transition to higher circularity.

Focusing on a product's environmental or social performance during its life phase, different methods are developed. A well-known and widespread set of standards are the ISO 14000 families, including the ISO 14001 standard for environmental management. It is based on the PDCA cycle (Plan, Do, Check, Act). ISO 14001-certified organizations must document all activities, including products and services, that may affect the environment [42]. ISO 14001 is a standardized environmental management system (EMS) focusing on processes within a company, life cycle assessment (LCA) is product oriented [43]. MFA is an industrial ecology method to identify material flow in a system. The material can focus on chemical substances, but also natural and technical compounds [44]. For the first case, this may be coined substance flow analysis (SFA). The system aspect has a strong link to system theory. The flow analysis can be done on a national or regional scale. Nevertheless, it can also be done within a corporate or within an industry. In that case, the supply chain aspect has relevance. EMS, LCA, and MFA are all data oriented meaning that the quality of the work depends on the quality of the data [45-47], using both company-specific data and industry average data.

Bill of material (BOM) and routing are two important concepts in the manufacturing industry, representing a list of a products and operations needed to create the product. They are core master data in manufacturing, and part of all ERP systems with a manufacturing module. There are typically several variants of a BOM. The green bill of material (Green- 
BOM) includes environmental attributes such as substance usage, possibility of reuse, energy performance, environmental emissions, hazardous substance, and reusability [48] Other types of BOMs are service BOM and sales BOM. Furthermore, BOMs are divided into single-level and multi-level. Manufacturers may have several levels in their structure down to the smallest representation needed for their operations. For purchased components, no $\mathrm{BOM}$ is required by the manufacturer. However, the BOM is typically available at the supplier. Both BOM and routing are a manufacturer's intellectual property, which they typically are reluctant to share with other companies [49]. Nevertheless, there are strong arguments to share the environmental and social aspects of BOMs and routings for a more sustainable future.

\section{Methodology}

To answer the research, we developed a conceptual model for product life phase information flow. Conceptual models are used within several research disciplines. Within computer science and information systems tradition, these models are used in the requirements analysis phase of information systems development [50]. Conceptual modelling is often used within the e-waste regime both for illustration of the phenomenon and for improvement. Parajuly et al. focus on the product family approach in their model for material recovery [51]. Song et al. focus on e-waste management in their framework for optimizing e-waste management in China [52]. Their focus is from a life phase perspective. In Islam et al.'s comprehensive literature review of e-waste as a logistic phenomenon, they identify 22 studies they define as conceptual frameworks [7]. They further classify the frameworks based on the different focuses: Logistics, remanufacturing, recycling, organizational perspective, the formal or informal sector, and product return. For our research purpose, a conceptual model was made to illustrate how improved information flow in a supply chain can improve the circularity level of products. A weakness of conceptual models is their validation. Logical and theoretical arguments can be used, but empirical validation is also necessary [53]. To validate this conceptual model, we used a case study following real e-waste flow for a real product involving semi-structured interviews and business document collection. We selected a product of which we had in-depth knowledge for two reasons. One, the product was going to be substituted by new equipment at our workplace, and two, one of the authors had previously worked at the OEM manufacturer delivering the equipment to be substituted and consequently becoming e-waste. To investigate the reverse supply chain, we made an initial list of stakeholders involved, and this list was extended during the interviews as we discovered actors involved. The resulting actors investigated were the original equipment manufacturer, EEE installer, waste collector, and recycle facility. To validate the distributed ledger part of the model, we needed competence on a level of detail that could ensure it would work in a real operational business environment. We used our connections to the Norwegian Bitcoin and Blockchain Association. Its leader is also the $\mathrm{CEO}$ of a Blockchain as a service company that provides industry-strength software solutions needed. We sent specific operational requirements via e-mail, followed by a 30-min interview in an e-meeting that verified the soundness of the model. In total, 5 companies were interviewed, with a total of 8 persons, as summarized in Table 3 . The original equipment manufacturer operates in the lighting industry, covering three of the WEEE categories (lamps, large equipment, and small equipment). 
Table 3. Interviews, companies, stakeholders, and type.

\begin{tabular}{ccc}
\hline Company & Title of Interviewee/Stakeholder & Type \\
\hline & Product manager & Phone/E-mail \\
Original Equipment Manufacturer (OEM) & Product manager & E-mail \\
& Eead of product management & E-mail \\
& Product Engineer & Phone \\
Reverse Supply Chain Actor 1: EEE-installer & Representative from the EEE-installer & Phone \\
Reverse Supply Chain Actor 2: Waste collector & Representative from the waste collector & Phone \\
Reverse Supply Chain Actor 3: Recycle facility & Representative from the recycle facility & E-mail with conceptual model \\
Blockchain as a service company & Business manager, CEO & Zoom meeting \\
\hline
\end{tabular}

\section{Fundamental Principles}

This paper investigates how a manufacturer can take on its responsibility to achieve circularity for its products. Based on our findings, three fundamental circularity principles, the CEEE principles, for manufactures of EEE are defined. Moving towards circularity calls for research on meeting the manufacturer's challenges, managing products, implementing restorative actions, and developing infrastructures.

\subsection{Serialized Product Identifiers-CEEE Principle 1}

Since the MoL of each product is affected by the experiences in the operational environment, each product has a unique life affecting its quality condition and its circularity potential. Therefore, information must be managed for each unique product across its $\mathrm{MoL}$ stages, requiring each product to have a serialized e-Product identifier.

Product identification must ensure that a product can be globally identified through a unique serialized identifier to achieve circularity. A unique identification ensures that product and information flow can be managed on the item level. Unique identification and labelling by manufacturers throughout the value chain enable implementation of cost-efficient circularity actions. Therefore, manufacturers should label their products according to global standards for identification, the dominant standard trade products being the Global Standard 1 (GS1) serialized global trade item number (SGTIN) [54].

For certain e-products, globally unique identification, such as the International Mobile Equipment Identity (IMEI) number for mobile phones, exists [55]. The IMEI number enables information to be retrieved via the internet. These numbers are governed by network operators under the global industry body Global System for Mobile Communications (GSMA) (https:/ /imeidb.gsma.com/imei/index accessed on 30 August 2021). The information retrieved by an IMEI lookup is typically the manufacturer, model, and product specification.

Product $\mathrm{C}$ in Figure 3 utilizes parts from remanufacturing or recycling of products $\mathrm{A}$ and B. Goltsos et al. found that serialized product identifiers allowed for more accurate parts availability data improving forecast accuracy benefits [56]. Maintaining information on each product via a serialized identifier facilitates automatic and cost-efficient disassembly in remanufacturing and recycling. Notably, a DL transaction address, introduced in the next section, also can be used as a unique identifier, which enables direct, and thus fast, look-up of product information in the DL. We denote the need for manufacturers to define serialized product identifiers in CEEE principle 1.

\subsection{Edge Data-CEEE-Principles 2}

Digitalization and digital transformation within manufacturing is often labeled Industry 4.0, where a set of emerging technologies for the manufacturing industry has been introduced. Gerbert et al. [57] defined nine advances in technology that form the foundation for Industry 4.0: Big data and analytics; autonomous robots; simulation; horizontal and vertical system integration; the industrial internet of things; cybersecurity; the cloud; additive manufacturing; and augmented reality. They point out that although several of these 
advances in technology are in use in industry today, in Industry 4.0, the technologies will be integrated and automated, changing the relationship between customers and suppliers and between humans and machines. A digital twin is seen as the virtual part of a cyber-physical systems (CPS) [58]. Distributed ledger and blockchain technologies may have the ability to solve challenges for which security and trust remain problematic. Moreover, within Industry 4.0, blockchain technology may be useful [59]. The three Industry 4.0/emerging technologies, vertical and horizontal system integration, digital twin, and blockchain, may all be suitable to improve product life phase information flow in a transition to circularity.

The EPR concept requires sharing information across independent actors, which is a classical challenge of extended supply chains [60-62]. The e-Product owner, remanufacturer, and recycler want complete information on the product, while the manufacturer is only willing to share selected information. The lack of willingness to share is a growing challenge since implemented IoT technologies generate considerable data at manufacturers that can be useful for other actors. In the emerging edge computing paradigm, each source (i.e., edge) acts on data at the source. This gives complete control by the authoritative source of the data that enables a distributed network of edges/sources that lets its enterprise applications control the internal data sources while filtering data that they are willing to share with other actors. This proximity to data at its source can deliver the business controlled access to data [63]. To keep the manufacturer in control of its data, an edge portal is an element in a decentralized network of edge portals for other actors with their authoritative data stored and shared in a controlled manner. Thus, the e-Product data relevant for circularity at the manufacturer can be controlled by an edge server portal. Since the e-Product data are maintained per item (serialized), the data at the edge portal are a digital twin of the e-Product, handling product circularity information that can be shared externally. Using an edge portal, the e-Product manufacturer can fulfill its responsibility related to the EPR regulation. We denote the use of an edge portal for CEEE principle 2.

The main challenge at EoL is to have a cost-efficient system that facilitates product circularity $[19,56]$. A promising technology that fits well as a central component for a system that handles the extended producer responsibility is DL technolgy.

\subsection{Public Distributed Ledger/Blockchain-CEEE Principle 3}

The extended part of EPR is not straightforward since, by definition, it extends beyond the manufacturer's business to a distant, typically unknown owner of the e-Product. Industrial e-Products, like luminaries, are typically long-lived with life expectancies of more than 20 years. Contemporary e-Products at their EoL are normally marked with a serial number and product type, possibly with the manufacturers' name. An e-Product owner as well as remanufacturers and recyclers could search for information on how to handle the product at EoL. Often, the manufacturer's website has some information, like in our case study, but sometimes the manufacturer does not exist anymore resulting in a "404 Not Found" response when an actor attempts to follow a dead link. Persistent availability of information across independent actors is a challenge that hampers extended supply chain operations in general [60-62]. No traditional "off-the-shelf" information systems exist to meet the challenge of having persistent e-Products over time that support information on EoL treatment.

DL technology fits this need well, as a strength of the DL is handling multiple independent parties that need to exchange information, where the DL provides a common database of time-stamped records. Numerous DL solutions are emerging. For the e-Product information system presented here, we have adopted the bitcoin blockchain as its DL blockchain technology has been running continuously since its beginning of life (BoL) in 2009 [64].

Information is shared via DL in a reliable and secure manner ensuring trust among actors, as highlighted by a number of researchers including Wang et al. (2019) [65]. Their research emphasizes that the DL properties for sharing information and building trust are (a) a single data pool available to all actors, (b) a highly secure system, (c) high data quality 
standards, and (d) built-in trust that helps brands gain customer confidence. We denote the use of a distributed ledger as CEEE principle 3.

\section{Edge\&DL, a Conceptual Model for Model for Handling Extended Producer Responsibility (EPR)}

The conceptual model aims to answer the research question mentioned in Section 2. This model is inspired by Wang and Wang [66,67], but here we focus on information sharing in the external supply chain. In their 2014 study, Wang and Wang propose a WEEE remanufacturing cloud system. The system not only covers the material recovery process, but also focuses on component recovery and reuse. The study includes a WEEE data model. In their 2019 study, the concept was extended, and individual WEEE was represented as a digital twin. Furthermore, a data model was included. In a recent study, Magrini et al. [68] combined the Internet of Things and blockchain technology in a Blockchain of Things (BCoT) approach. Our conceptual model is positioned in this landscape, but one of our main focuses is establishing core principles for the reuse and sharing of existing information. We illustrate how controlled sharing of information along the supply chain can provide the necessary data along the chain for a manufacturer to assume its responsibility.

Sharing data in supply chains and manufacturing networks is often handled by cloud-based systems. Technically cloud-based systems may enable this sharing, but the protection of intellectual properties may be a hindrance, and the originators of the data are reluctant to put valuable information in external systems [60-62]. Solutions that secure a firm's intellectual property are needed. Bogers mentions licensing agreements as one solution when he investigated knowledge sharing between different supply chain actors in research and development processes [49]. Blockchains may have potential to secure firm's intellectual property [69]. Much of the information about how to recycle, remanufacture, or reuse is already available along the supply chain in internal systems at relevant actors in their enterprise systems (e.g., PLM, ERP), but there is a lack of mechanisms to manage this information in a manner in which all actors within the chain approve. Each component in a product, using the manufacturer's BOM and routing, are represented as a "sustainable digital twin", handling the product's circularity information. The twin (on all levels) holds information about the content as well as the remanufacture, reuse, or recovery. Environmental and social parameters for the products (i.e., $\mathrm{CO}_{2}$ footprint and warranty that child labor has not been used) can also be included.

Manufacturing systems have been developing since the 19th century from production by a single manufacturer using raw materials as input to make the finished product [70], to the current manufacturing networks consisting of a range of highly specialized manufacturers each producing a component of the finished product followed by an increased focus on collaboration among actors [71,72]. Over the years, companies have found it cost efficient to specialize on core competencies while outsourcing supporting activities, thus adding an increasing number of connections, resulting in a global network of manufacturers. Manufacturers have become assemblers since a major part of their products are assembled by parts from suppliers. This role is evident with the large portion of the value creation devoted to purchasing. In the EU in 2015, the 2.1 million enterprises classified as manufacturers spent an average of $74 \%$ of their turnover on purchases of goods and services [73]. Generally, we recognize this as the $80 / 20$ Pareto principle for all companies in the manufacturing sector: $80 \%$ assembly and $20 \%$ physical transformation of materials or components.

Although information handling within each manufacturer is well managed by enterprise systems, inter-company information exchange still faces challenges of lack of standards, off-the-shelves, IT systems to support it, low willingness by actors to share information to protect their IPR, and asymmetric benefit/value realization. Providing information for others comes at a cost, while the value is gained by others. In addition, the range of proprietary systems tailor-made for inter-company information exchange typically struggle to reach a critical user mass. Current proprietary tailor made solutions include hub systems (e.g., Norwegian Oil and Gas LogisticHub), EDI point-to-point so- 
lutions for exchanging business documents, the Global Data Synchronization Network (GDSN) (https:/ / www.gs1.org/services/gdsn accessed on 30 August 2021), data pipeline systems [74], and sliding window protocols. The manufacturing networks perspective is complex with many actors, each with their own information system architecture with different user interfaces, business logic, and data models.

\subsection{The Product Perspective in Our Case Study}

A product adhering to the CE model passes through several life phases. Even if products move through life phases in a circular fashion, from the products' point of view, their life is arranged in a time-sequential linear order. Along the life, circularity events occur at specific points in time that affect the product. For most industrial products, life contains few events from when they are born (i.e., when they receive a product identity), through their life with maintenance event, to their EoL when they are remanufactured or recycled. Since both remanufacturing and recycling may involve disassembly, a products' unique identity ceases to exist at EoL (but its components live on). The number of events along an industrial product's lifeline is few and thus simple to track. In this paper, we introduced an Edge\&DL model involving an edge computing system at each actor, circularity events, and a DL to log events accompanied by links to product information at edge actors. A case study is used to validate the proposed Edge\&DL model.

To use the information in the DL, an application that runs through the DL is needed to find event information related to a specific product. This information informs circularityactions at the appropriate circularity actors.

\subsection{Circularity Event Example}

All information relevant to product circularity should be made digital available to the appropriate actors. Product MoL monitoring such as usage, maintenance, and wear and tear information is stored by the actor who is the data source. These data are made available for others in a controlled manner by requests to their edge portal using the serialized product identifier as key.

Finding data captured at the edge from different sources is realized through a persistent data register (DL/Blockchain) that, for each event, stores the serialized product identifier and associated information on how to connect to the relevant actor. The events affecting a product are organized as transactions in time in the DL since the DL functionality gives a time stabling service and each party makes data accessible at their edge portal and these data can be accessed via the Product_Serialized_ID stored in the DL and tagged on the product.

Thus, access is controlled by each actor at their edge portal using security technology so only actors authorized by the actor gain access to the data. Typically, a maintenance service company uses such an authorized party. Hence, on the maintenance service side, the product circularity data are available when access is granted. On their side, they keep enriched maintenance data, which may be relevant circularity information for other actors. This paper proposes an Edge\&DL model that works as a circularity information infrastructure and leads to the availability of reliable circularity information.

We illustrate with a case study of a lighting EEE in which circularity data have a positive effect on fostering product circularity. During the work on this paper, the institution where the authors are employed upgraded parts of their lighting equipment. The original equipment was conventional luminaires with light sources. The new equipment was LED based, with sensors for smart light control; on its own, an environmental improvement. The old lighting equipment was delivered when the building was built in 1994. Although the replaced product had been out of production for many years, much information was available from the manufacturer's web page. We found the following information about the product model: Certificates, user manuals, product sheet, building information modeling (BIM) files, technical description, photos, and light technical data. Two of the documents were relevant for EoL treatment. A product sheet included the products weight and 
volume, body material, electrical data, light data, and an exploded view of the product to illustrate how it was assembled. Both documents provided valuable information related to product remanufacturing or recycling. Examples of these documents are provided in Appendix A. We contacted the manufacturer of the lighting equipment and asked for additional documentation. We were especially interested in the BOM, the routing (for the assembly sequence indicating a disassembly sequence), and CAD drawings of the luminaries. The interviewed product engineer informed us that "without a unique identification of the products, it is not straightforward to find such information since the lighting equipment has been produced in thousands of variants" (Translated from Norwegian).

By a unique identifier, the manufacturer meant identification of the unique product model, as they do not use serialized product identifiers. We did not find a unique identifier for the product model so the manufacturer could not guarantee that we received the correct versions of the documentation. The manufacturer also explained that the information we had found on their web site might not be 100\% relevant for our product since we did not have the unique product identifier. This experience demonstrates the need for better product identification and labelling, and more recent products from the manufacturer are labeled with unique product model identifiers. For future circular processes, finding more precise documentation for the correct product model from the manufacturer is more likely. The manufacturer had no information on the MoL phase, and we failed in finding such information from the product owner at EoL.

There was also a challenge related to other products from the manufacturer. The manufacturer had completed several acquisitions of other manufacturers over the years. As a result, some expired products from acquired manufacturers were not fully documented. This issue exemplifies the need for a register to catalogue product serialized identifiers and at least associated information identifying who is currently responsible for EoL treatment.

The forward supply chains within the lighting industry are, as most supply chains, challenging to follow. In this case, the building owner purchased luminaries from an installation company. The installation company purchased the goods from a wholesaler, who again purchased from the manufacturer. The installation company did not only deliver and install the equipment, but they also provided documentation about the installation. In addition, they handled the equipment after EoL.

We traced the flow of e-waste. Talking to the installers replacing the old luminaries with new ones, we were informed that they removed the light bulb parts and batteries from the old equipment and delivered them to a collector. They did not report anything about the equipment, nor the owner, and they were not charged for delivering the EoL equipment since a fee for handling the EoL treatment was covered by the collected environmental fee. The collector explained that they roughly sorted the equipment. Bulbs, batteries, and the remaining luminaries were sent to three different recycle facilities. The WEEE was sent to a recycling facility located in the region, but for other special products, some were shipped outside the region. The recycle facility could inform that they removed some material (e.g., cables), separated, compressed, and sent the material for metal recovery. All the WEEE we investigated was treated anonymously in the sense that it was not linked back to the manufacturer, nor to the owner. The WEEE/e-waste flow of our case is illustrated in Figure 5 .

The actors' need for information in their current operational mode is limited. Their main circular strategies are recycling metal and recovering energy by burning. Reusing or remanufacturing is not present in the current handling. 


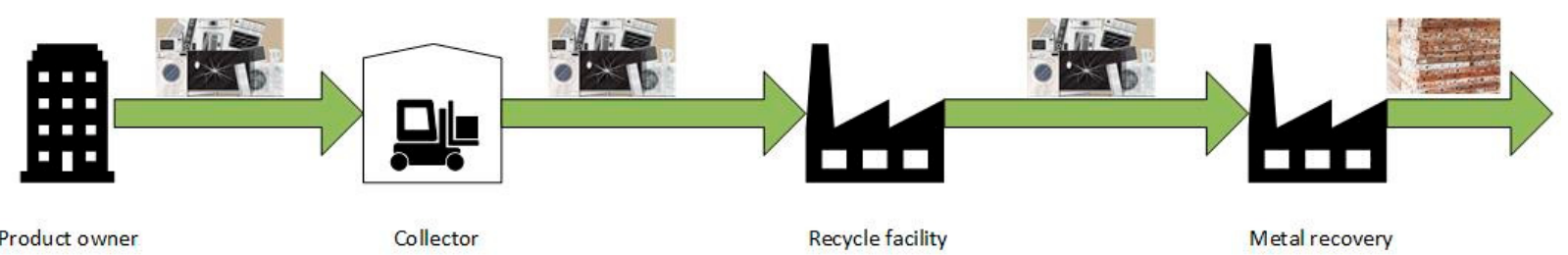

Figure 5. WEEE/e-waste flow of luminaries after EoL identified in the case study (Illustration: Colourbox.com (accessed on 30 August 2021)).

To increase the circularity level (e.g., by automated disassembling that captures the value of the parts enabling remanufacturing), more information about the disassembly process is needed. Manufacturers currently hold much of this information, and they could easily make dedicated information for circularity. However, since the time from production to reuse or remanufacturing is long (27 years in our case), the necessary information has not been structured and organized to be available for actors. A persistent storage mechanism is needed. The information should also be organized to be machine-readable to secure automated information flow without human interaction. This step is crucial to secure cost-efficient circularity actions that can handle low value products. Figure 6 illustrates a solution supporting circularity in which all actors within the forward and reverse supply chains communicate via the Edge\&DL model. For each stage in a product's life, the different actors can write to the DL using the Product_Serialized_ID as a key. The forward supply chain on sales and delivery is depicted with blue arrows, while the reverse supply chain is shown with green arrows. The different actors may find further information about the product and its handling procedures by reading the Product_Serialized_ID from the product and using it to search for the information in the DL.

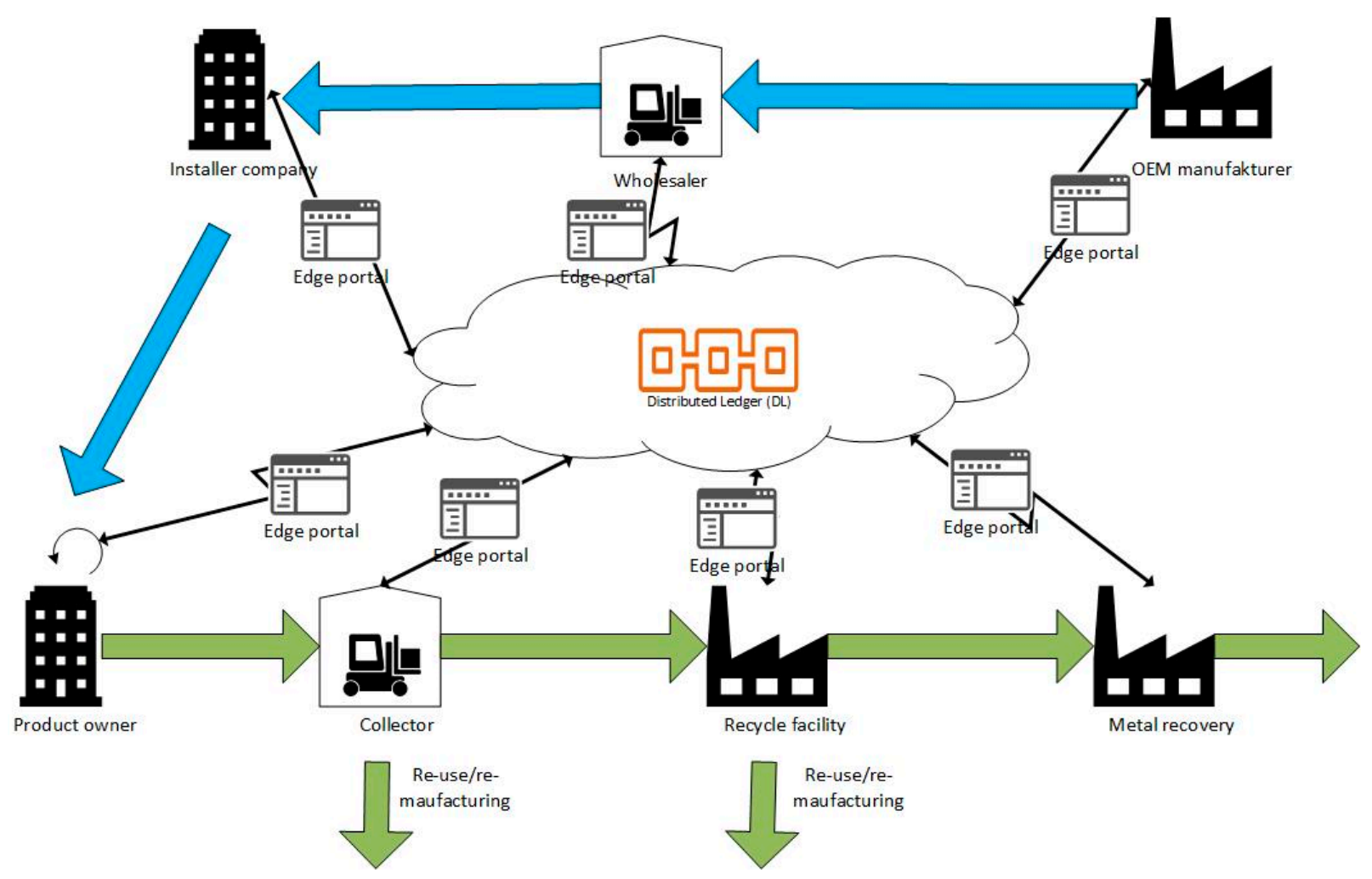

Figure 6. Information flow in a forward and reverse supply chain to make it circular (Illustration: Colourbox.com (accessed on 30 August 2021)). 
The Edge\&DL model supports various functionalities. For example, before eventual replacement, the product owner may ask the DL about product upgrade opportunities. This option supports the reuse circularity actions and extends the products MoL. Alternatively, the collector may check the products potential for reuse at other locations and the potential value of remanufacturing or recycling the product before deciding to replace it. The same check can be performed by the recycle actors. Through all options, a unique serialized product identifier is the key for the product. As in our case study, all communication with the DL must be performed for each product. To make this supply chain circular, all the green arrows pointing out of the figure should go to back to actors in the supply chain. A detailed model of how the edge portal communicates with the DL is shown in Figure 7.
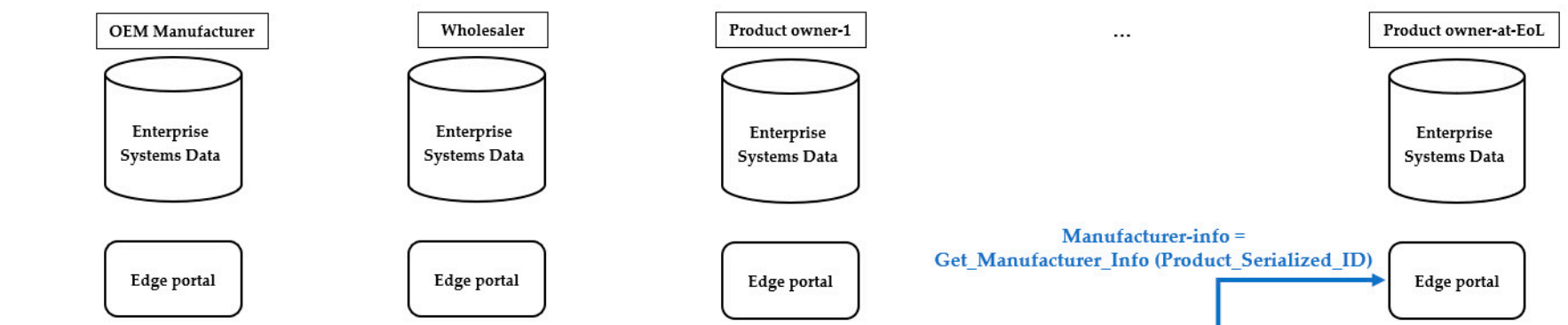

Manufacturer-info $=$

Get_Manufacturer_Info (Product_Serialized_ID)
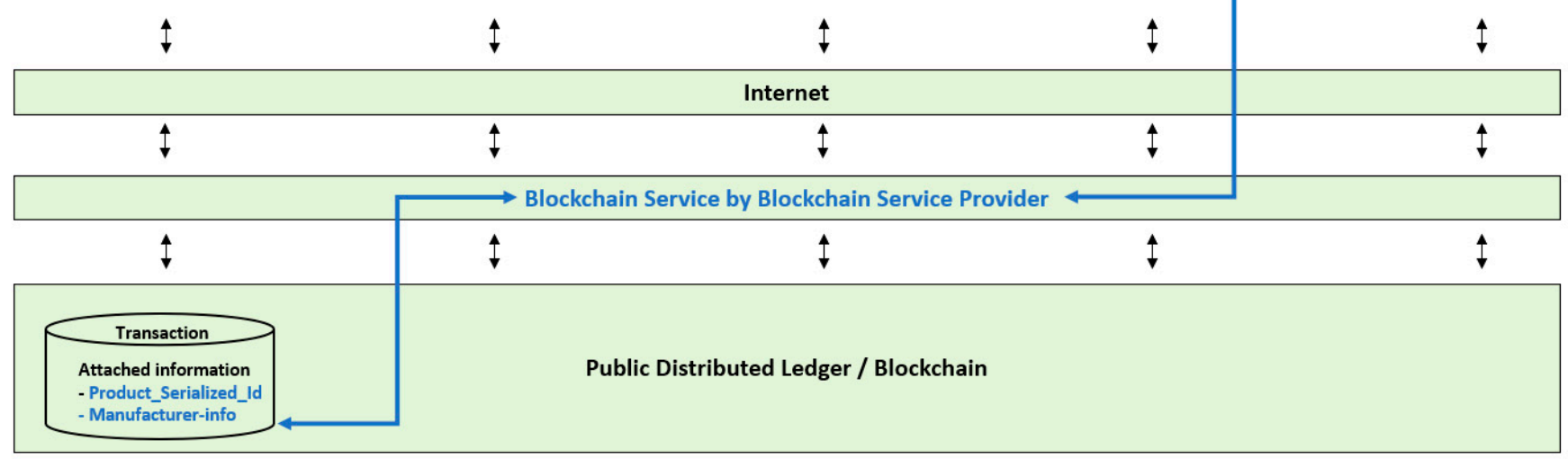

Figure 7. Detailed illustration of finding information stored in the DL by using the function Manufacturer-Info = Get_Manufacturer_Info (Product_Serialized_ID).

The information flow without an Edge\&DL model is modelled as an AS-IS scenario in Figure 8. This model clearly demonstrates that there is no flow of product information from the initiation of the purchasing process to the execution of the EoL handling process. Furthermore, Figure 8 highlights that there are no links between the stages in a product's life (BoL, MoL, EoL). The information flow is limited to the closest actors within the forward and reverse supply chain (one-up, one-down). Figure 9 provides a model of a future situation in which the Edge\&DL model is used as a TO-BE scenario. Here, the information from the purchasing process relates to the EoL process. Each actor in the delivery process has internal information on how it handled the product. By using the Product_Serialized_ID as a key, an actor can store a link in the DL that enables other actors to find the product via the same Product_Serialized_ID. In this model, the manufacturer, the wholesaler, the installation company, and the product owner are the actors in the BoL phase. The product owner and eventual other MoL actors, like maintenance service providers, provide the Edge\&DL with information in the MoL phase of the product. 

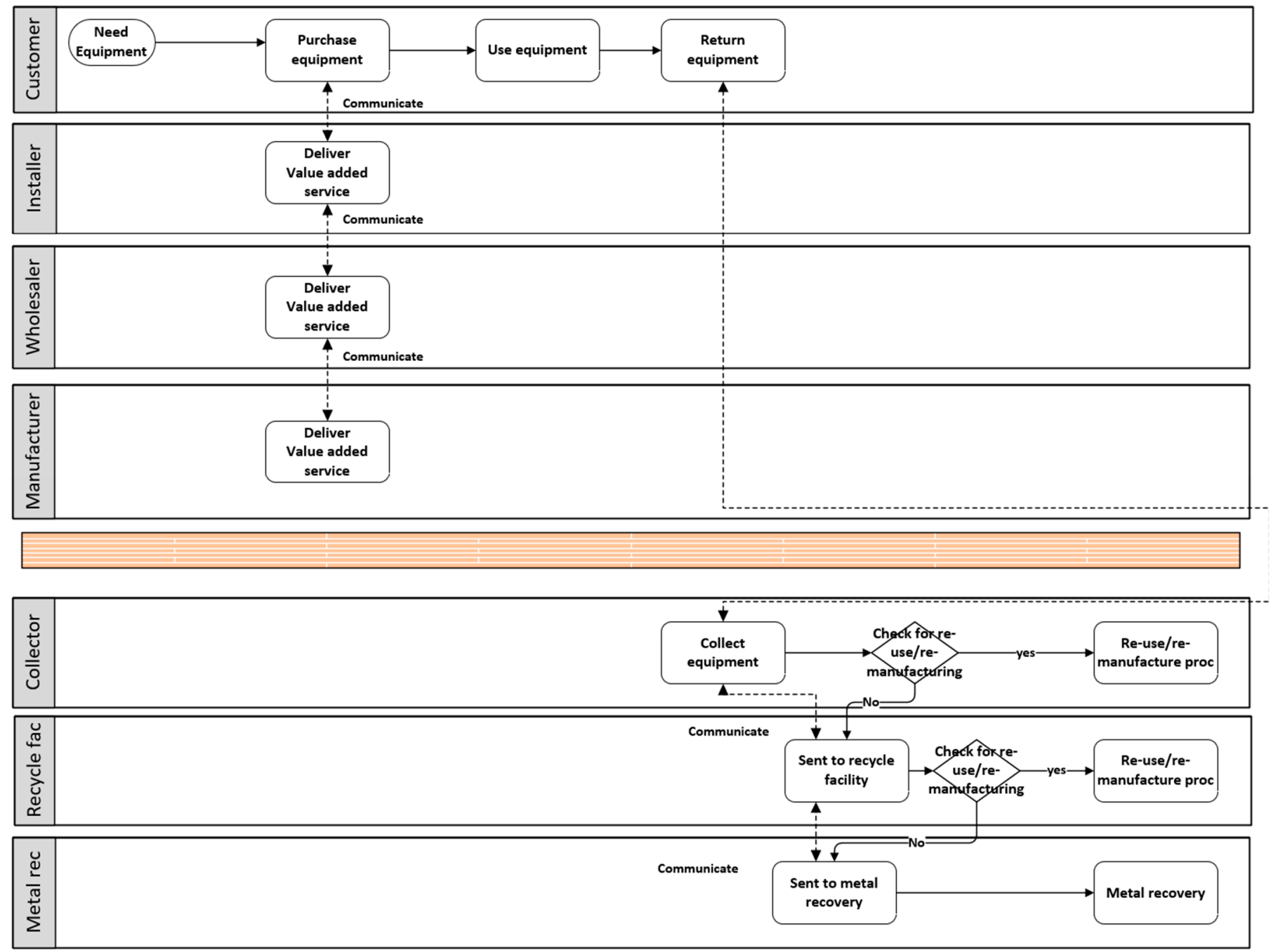

Figure 8. Process diagram of existing information flow in e-waste/WEEE handling.

In the EoL phase, remanufacturing and recycling actors use the Edge\&DL model. Some critical decision points in the reverse supply chain are making decisions based on information obtained by the Edge\&DL model. Remanufacturers, recyclers, and waste handlers may decide the appropriate circularity action before they send the product to the actor implementing it.

There might be more actors, like forwarders and consulting companies. The transaction events are stored in the DL, with links to further information in the edge portals. When the products leave the owner for certain reverse processes, new events are registered in the DL. At the same time, information from the manufacturer about circularity strategies, such as re-use, re-manufacturing, recycling, or recovery, can be read from the Edge\&DL model using the Product_Serialized_ID as a key. This regime establishes a link between the manufacturer and the user/owner of a product. The availability of circularity data is also beneficial for government inspection agencies because it enables them to automate circularity assessment by accessing the Edge\&DL model, resulting in more precise data. This enables taxation initiatives for positive or negative agent behavior. 


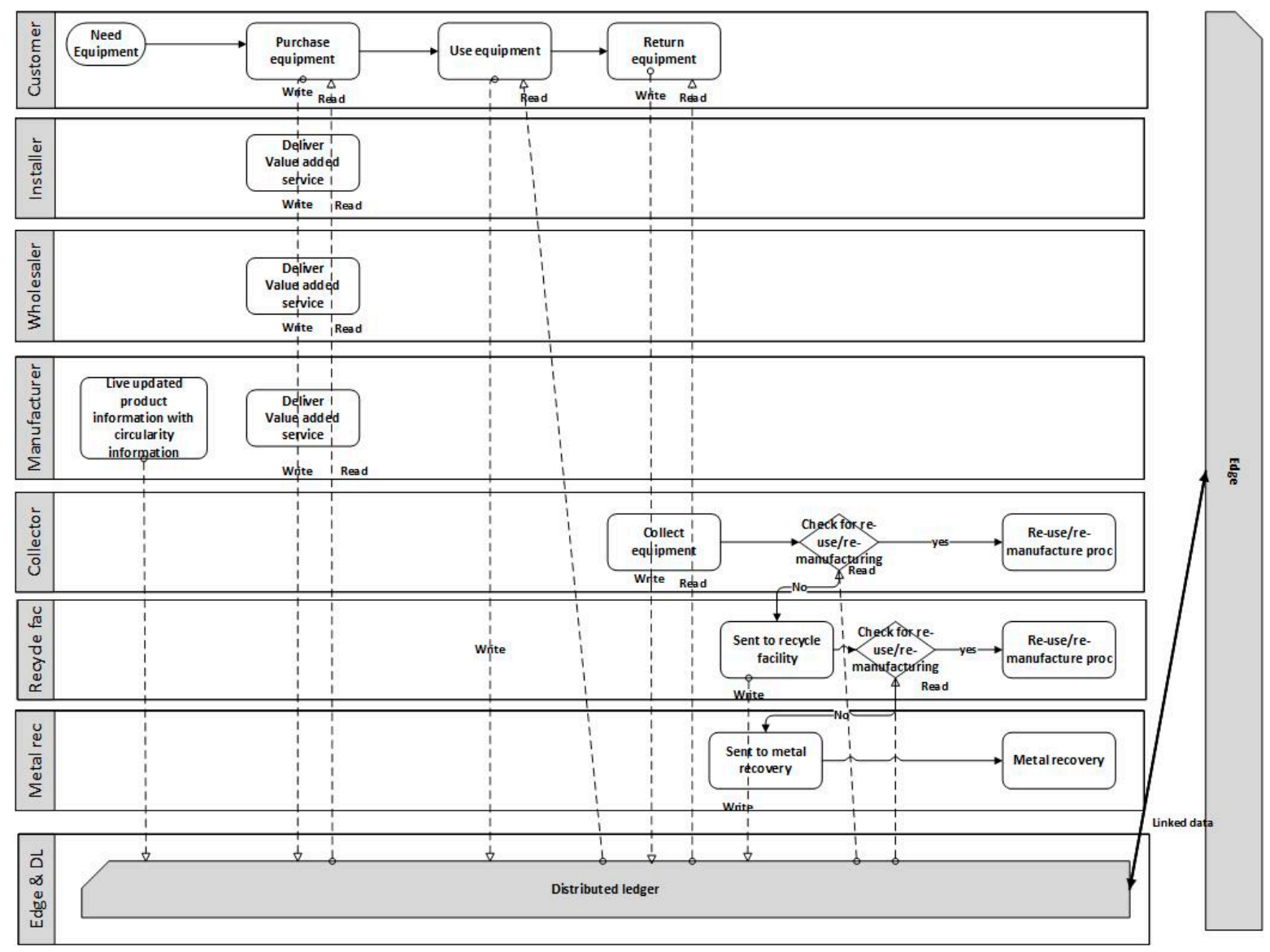

Figure 9. Process diagram supported by Edge\&DL for e-waste/WEEE handling.

Moreover, the Edge \& DL model will not affect existing information systems or the information in them for the actors along the supply chain, nor will the system expose each actor's internal business processes. Each actor only exposes information relevant to increase circularity via its edge portal. The DL tracks the events and the transactions, while the edge gives supplemental information.

The Edge\&DL model has three fundamental pillars: First, the solution must be built on service-oriented software (SOA) to access the edge/source data. This requirement secures the individualities from the edge and backward the manufacturers system portfolios. Second, unique serialized product IDs are needed to link products to the information made available via the edge portal. This information is currently fragmented throughout the actor network held in their intranet information systems. Figure 10 provide examples of various data sources for the edge portal in an SOA oriented system. Third, the solution must be based on a federated method of information exchange. The DL is a federated information system solution; the data remain with the individual actors responsible for the data-linking through linked data references that enable common access, adhering to the FAIR principles (findable, accessible, interoperable, and reusable) (https:/ / www.go-fair. org / fair-principles / accessed on 30 August 2021). An actor's internal data are transformed to comply with the FAIR principles by the edge portal. For example, some product circularity data are made available by a manufacturer through the Product_Serialized_ID labelled as a barcode, QR code, or RFID number attached to the product. These data can be captured by a smart phone scanner or similar scanner that uses the Product_Serialized_ID to find a link to the source/edge information in the DL. The edge portal responds only to authorized requests. Each company has their own information system architecture with different user interfaces, business logic, and data models. Since the edge portal is accessed via the DL, these aspects do not need to be directly involved. 


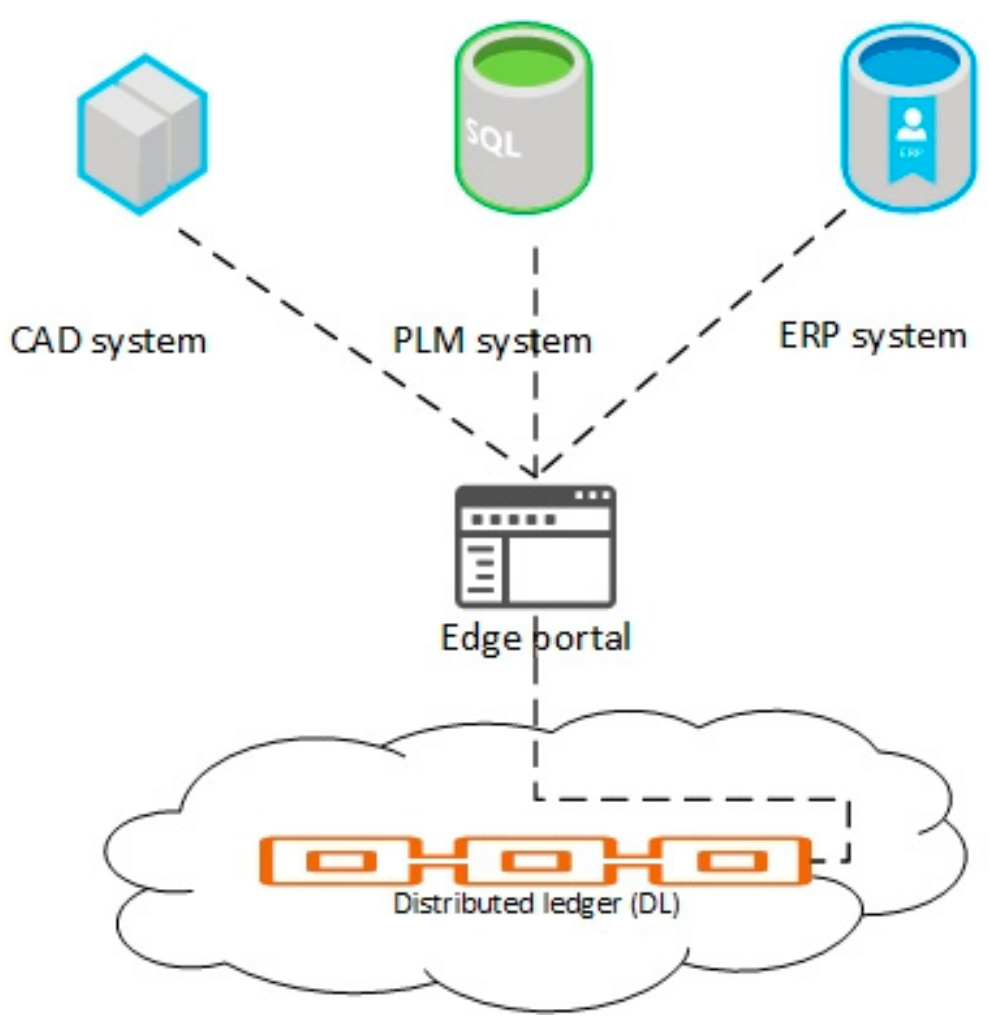

Figure 10. Examples of various data sources for the Edge\&DL solution (Illustration: Colourbox.com (accessed on 30 August 2021)).

\section{Discussion}

Manufacturers play a key role in the transition to a circular economy. They need to take explicit responsibility for products throughout the entire partner network from cradle to grave [75]. This includes the establishment of a restorative system for handling their products as well as their components. The intention of the proposed Edge\&DL model is to support the manufacturers in their efforts to build a restorative system that involves suppliers, product owners, maintenance service providers, remanufacturers, and recyclers. In addition to the extended producer responsibility, a restorative system must consider other objectives such as profits, product and service quality, and intellectual property rights. No standard system exists for how manufacturers can take on their extended producer responsibility in such a multifaceted network of objectives and actors.

We propose the Edge\&DL model for cradle-to-grave product management based on three circularity principles: (1) Serializing product identifiers, (2) storage and control of data at the edge, and (3) utilizing a distributed ledger to link a product to information about the product.

The first principle, to serialize product identifiers, is a strict requirement to enable manufacturers to take on their extended producer responsibility. It must be applied in a recursive, nested manner for a single product and its components being products supplied by other manufacturers. This supports the call by Islam et al. [7] for product-specific network models and product-oriented studies. Only by having a unique identifier on each material can products be managed across several actors [54,76].

The second principle, the storage and control of data at the edge, is seen as a solution to the objectives of responsibility, profits, quality, and intellectual property rights. Enabling manufacturers to control sharing of their own data respond to the traditional lack of willingness to share information via third-party cloud solutions that are hampered by issues like data ownership, data maintenance, and persistence over time $[66,77,78]$. We argue for a different approach, the edge data principle, in which the originator of the 
data stores and controls the data. This concept is strongly linked to IoT technologies and machine-to-machine communication [79], with arguments on using this to obtain higher degree of circularity [80].

The third principle, utilizing a DL to link a product to information about the product, is a promising technology with increasing focus. It supports persistent, transparent, and decentralized data storage and access over time in a manner that decouples the storage from the manufacturers, the owners, as well as other actors. Studies using DL with various circularity strategies have been identified [81], even if real-world use cases are still uncommon.

The soundness of the Edge\&DL model has been verified by actors in a reverse supply chain of electrical and electronic equipment and by a blockchain service provider on the detailed implementation of the storage and retrieval distributed ledger operations.

\section{Conclusions, Limitations and Directions for Future Research}

We investigated the research question on how an EEE manufacturer can take on its extended producer responsibility to achieve circularity for its products. Answers were sought by investigating how manufacturing industries currently handle their responsibility. The research into achieving this aim is rooted in recent technological improvements, known as Industry 4.0 or the fourth industrial revolution. We investigated the existing information a manufacturer has available, and the kind of system needed for this information to be shared along the forward and reverse supply chains to make it more circular. An Edge\&DL model was developed based on shared ledger technology and edge computing principles. The edge computing approach require storage information close to the authoritative sources of the data, while the DL technology provides a public shared database that stores unique serialized product identifiers serving as a link between the edge data source at each actor. The DL technology ensures information correctness and immutability and also has the proven ability to secure a firm's intellectual properties. The model vas validated via a case study from the EEE and WEEE industry involving a EEE manufacturer and a blockchain service provider.

Our contribution is a model the allows the manufacturer to assume its responsibility to handle its products throughout the product's live, extended over the external forward and reverse supply chains. The model enables management of the flow of existing information and orchestration for a higher circularity in products. We have established the three fundamental CEEE principles as follows. First EEE manufacturers are required to serialize product identifiers and store them in the DL with information on how to access the actor's edge portal; other actors are encouraged to do so too. Second, all circularity actors should let data be kept at the edge to allow controlled sharing via the edge portal. Third, all independent actors can find edge data from any actor via the distributer ledger using the serialized product identifier as a key. The Edge\&DL model was proposed based on the CEEE principles and a practical case demonstrating how the model can contribute to enabling manufacturers to undertake their extended product responsibility. The Edge\&DL model contributes to alleviating the classical information sharing paradox [49]: Even if it will benefit the whole chain, an individual actor is not willing to share information.

The waste focus of the WEEE directive originating in 2003 is not aligned with the current goal of circularity in which waste should be omitted. We propose an Edge\&DL model that enables circularity for electronic and electric products (CEEE) in a manner that lets the manufacturer assume its extended producer responsibility. The proposed Edge\&DL model is a contribution to how to enable an increase in circularity for both open-loop and closed-loop supply chains.

The conceptual model is mainly focused on the technical part of the Edge\&DL model. Incentives, laws, or regulations may be needed to encourage actors within the CEEE regime towards information sharing. Focus on this dimension and how this barrier can be broken down is not covered in this study. Further research in this direction is recommended. 
The case study only focusies on one e-waste case in one country. Expanding the case study with other cases handling other EEE categories and other countries should provide better insights into this area. The model is theoretical but verified by technology service providers. Developing a prototype/demonstrator to further validate the Edge\&DL model using real data from the supply chain is needed. Further, we recommend research on the governance of electronic and electric equipment that investigates how to refocus the waste perspective of the WEEE legislation toward a circular perspective in a CEEE legislation.

Author Contributions: Conceptualization, T.A. and B.J.; methodology, T.A.; validation, T.A. and B.J.; formal analysis, T.A., B.J.; investigation, T.A.; resources, T.A. and B.J.; data curation, T.A.; writingoriginal draft preparation, T.A.; writing-review and editing, T.A. and B.J.; visualization, T.A. and B.J.; supervision, B.J.; project administration, T.A. Both authors have read and agreed to the published version of the manuscript.

Funding: This research received no external funding.

Institutional Review Board Statement: The study has been registered to Norwegian Centre for research data (NSD). Participants have been informed that no names would be mentioned in the study.

Data Availability Statement: Interview data, both recorded material and the transcribed results are stored. Due to the agreement with NSD, data that can identify people will be anonymized or deleted latest 30 September 2023.

Conflicts of Interest: The authors declare no conflict of interest.

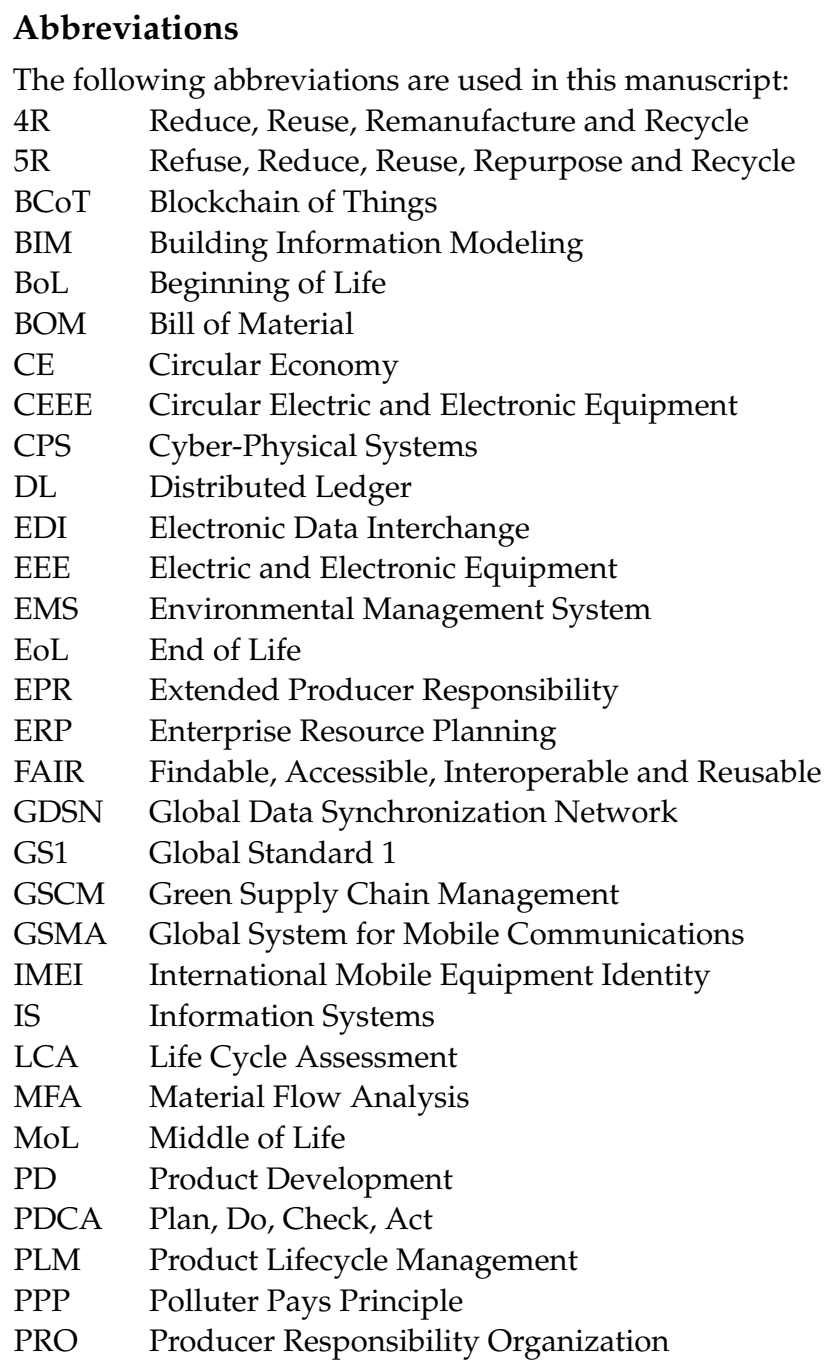


RSC Reverse Supply Chain

SC Supply Chain

SCM Supply Chain Management

SFA Substance Flow Analysis

SGTIN Serialized Global Trade Item Number

SOA Service-Oriented Software

SSCM Sustainable Supply Chain Management

WEEE Waste Electric and Electronic Equipment

Appendix A

\begin{tabular}{lr}
\hline Electrical data & \\
\hline Minimum Voltage $-10 \%(\mathrm{VAC})$ & 230 \\
\hline Minimum frequency $-5 \%(\mathrm{~Hz})$ & 60 \\
\hline Maximum frequency $+5 \%(\mathrm{~Hz})$ & 60 \\
\hline Maximum voltage $+10 \%(\mathrm{VAC})$ & 230 \\
\hline Total consumption $(\mathrm{W})$ & 88 \\
\hline Dimensions & \\
\hline Net weight $(\mathrm{kg})$ & 6,3 \\
\hline Height $(\mathrm{mm})$ & 96 \\
\hline Length $(\mathrm{mm})$ & 1247 \\
\hline Width $(\mathrm{mm})$ & 273 \\
\hline Technical data & \\
\hline Maximum ambient temperature $\left({ }^{\circ} \mathrm{C}\right)$ & 20 \\
\hline IP classification
\end{tabular}

\begin{tabular}{lr}
\hline Light data & \\
\hline Lamp power (W) & 36 \\
\hline Lamp base & 213 \\
\hline Number of lamps & $T 8$ \\
\hline Light source & \\
\hline Body & White \\
\hline Colour of body & Steel \\
\hline Body material & RAL 9016 \\
\hline Body colour code & 2 \\
\hline Ballast/Driver & \\
\hline Number of ballast/driver & High power factor correction \\
\hline Type of ballast/driver & 2 \\
\hline Termination & Grommet \\
\hline Number of blind plugs & \\
\hline Type of blind-plug & \\
\hline
\end{tabular}

Figure A1. Part of product sheet. Illustrations from (CGlamox.

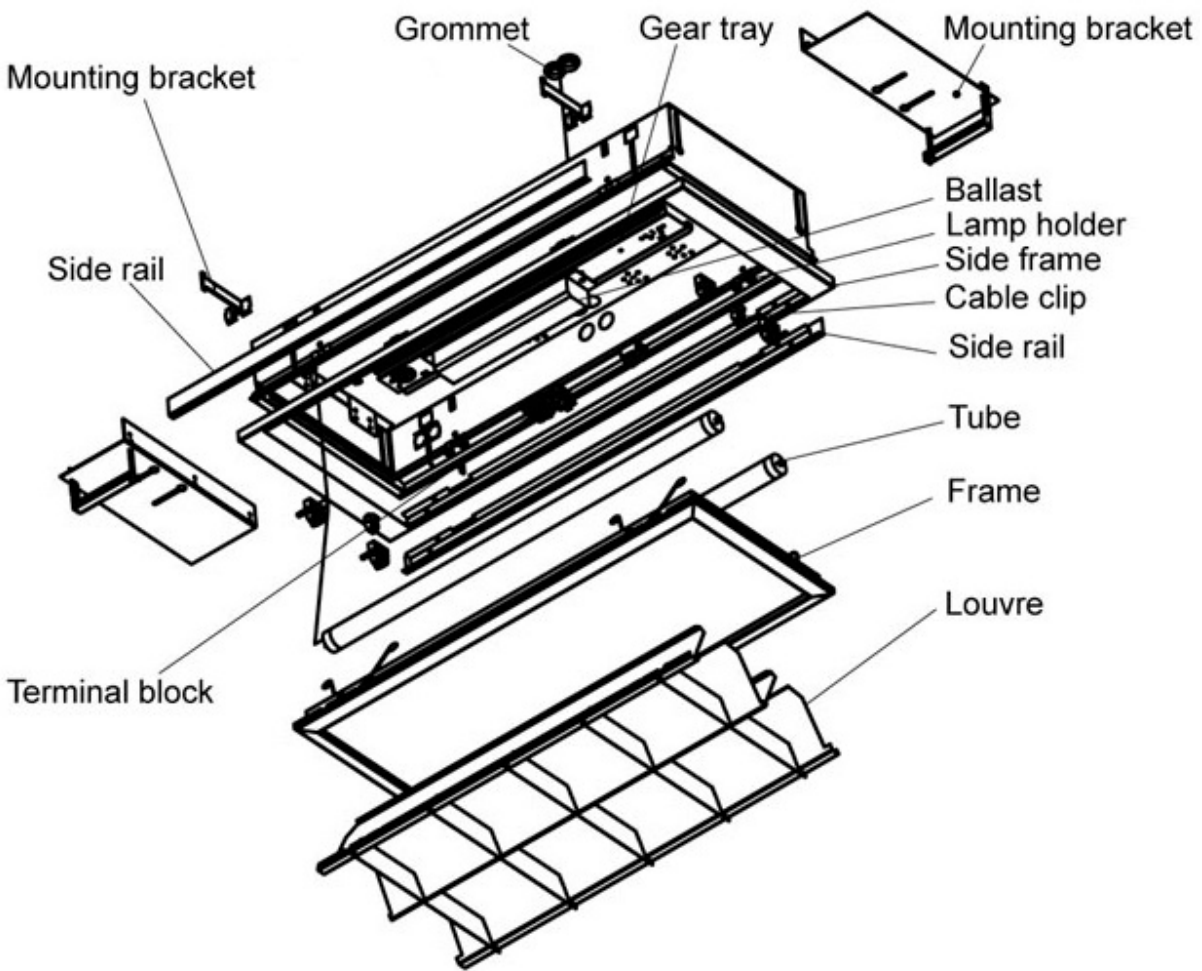

Figure A2. Product exploder view. Illustrations from @Glamox. 


\section{References}

1. Brundtland, G. Our Common Future; The World Commission on Environment and Development: New York, NY, USA, 1987.

2. Elkington, J. Partnerships from cannibals with forks: The triple bottom line of 21st-century business. Environ. Qual. Manag. 1998, 8, 37-51. [CrossRef]

3. Masi, D.; Day, S.; Godsell, J. Supply Chain Configurations in the Circular Economy: A Systematic Literature Review. Sustainability 2017, 9, 1602. [CrossRef]

4. Geissdoerfer, M.; Savaget, P.; Bocken, N.M.P.; Hultink, E.J. The Circular Economy-A new sustainability paradigm? J. Clean. Prod. 2017, 143, 757-768. [CrossRef]

5. Kumar, A.; Holuszko, M.; Espinosa, D.C.R. E-waste: An overview on generation, collection, legislation and recycling practices. Resour. Conserv. Recycl. 2017, 122, 32-42. [CrossRef]

6. Forti, V.; Balde, C.P.; Kuehr, R.; Bel, G. The Global E-Waste Monitor 2020: Quantities, Flows and the Circular Economy Potential; United Nations University: New York, NY, USA, 2020.

7. Islam, M.; Huda, N. Reverse logistics and closed-loop supply chain of Waste Electrical and Electronic Equipment (WEEE)/E-waste: A comprehensive literature review. Resour. Conserv. Recycl. 2018, 137, 48-75. [CrossRef]

8. Bressanelli, G.; Saccani, N.; Pigosso, D.C.A.; Perona, M. Circular Economy in the WEEE industry: A systematic literature review and a research agenda. Sustain. Prod. Consum. 2020, 23, 174-188. [CrossRef]

9. Andersen, T. A comparative study of national variations of the European WEEE directive: Manufacturer's view. Environ. Sci. Pollut. Res. 2021. [CrossRef]

10. Zeiss, R.; Ixmeier, A.; Recker, J.; Kranz, J. Mobilising information systems scholarship for a circular economy: Review, synthesis, and directions for future research. Inf. Syst. J. 2021, 31, 148-183. [CrossRef]

11. Diedler, S.; Hobohm, J.; Batinic, B.; Kalverkamp, M.; Kuchta, K. WEEE data management in Germany and Serbia. Glob. NEST J. 2018, 20, 751-757.

12. Ahi, P.; Searcy, C. A comparative literature analysis of definitions for green and sustainable supply chain management. J. Clean. Prod. 2013, 52, 329-341. [CrossRef]

13. Carter, C.R.; Hatton, M.R.; Wu, C.; Chen, X. Sustainable supply chain management: Continuing evolution and future directions. Int. J. Phys. Distrib. Logist. Manag. 2019, 50, 122-146. [CrossRef]

14. Rodhain, F. Electronic Waste Dumped in the Global South: Ethical Issues in Practices and Research. In The Path of Ethics In Research in Laos and Mekong Countries; French National Research Agency: Paris, France, 2018; pp. 95-101.

15. Geissdoerfer, M.; Morioka, S.; de Carvalho, M.M.; Evans, S. Business models and supply chains for the circular economy. J. Clean. Prod. 2018, 190, 712-721. [CrossRef]

16. Nabil Nasr, J.R.; Stefan, B.; Stefanie, H.; Brian, H.; Cory, K.; Nadia von Gries, R.P. Re-defining Value-The Manufacturing Revolution. Remanufacturing, Refurbishment, Repair and Direct Reuse in the Circular Economy. In A Report of the International Resource Panel; United Nations Environment Programme: Nairobi, Kenya, 2018.

17. MacArthur, E. Towards the circular economy. J. Ind. Ecol. 2013, 2, $23-44$.

18. Braungart, M. Creating Desired Futures, in Cradle-to-Cradle Design: Creating Healthy Emissions-A Strategy for Eco-Effective Product and System Design; Michael, S., Ed.; Birkhäuser: Basel, Switzerland, 2012; pp. 247-271.

19. Sharpe, R.; Goodall, P.A.; Neal, A.; Conway, P.P.; West, A.A. Cyber-Physical Systems in the re-use, refurbishment and recycling of used Electrical and Electronic Equipment. J. Clean. Prod. 2018, 170, 351-361. [CrossRef]

20. Bocken, N.M.P.; de Pauw, I.; Bakker, C.A.; van der Grinten, B. Product design and business model strategies for a circular economy. J. Ind. Prod. Eng. 2016, 33, 308-320. [CrossRef]

21. EFNMS. The European Federation of National Maintenance Societies. 2021. Available online: https://www.efnms.eu/about-us / what-does-efnms-stand-for/ (accessed on 30 August 2021).

22. Guide, V.D.R.; Jayaraman, V.; Srivastava, R.; Benton, W.C. Supply-Chain Management for Recoverable Manufacturing Systems. Interfaces 2000, 30, 125-142. [CrossRef]

23. Potting, J.; Hekkert, M.; Worrell, E.; Hanemaaijer, A. Circular Economy: Measuring Innovation in the Product Chain-Policy Report; PBL Netherlands Environmental Assessment Agency: The Hague, The Netherlands, 2017.

24. European Commission. Circular Economy Closing the Loop; European Commission: Brussels, Belgium, 2015.

25. European Commission. Revised Waste Framework Directive; 2008/98/EC; European Commission: Brussels, Belgium, 2008.

26. Andersen, T.; Jæger, B.; Mishra, A. Circularity in Waste Electrical and Electronic Equipment (WEEE) Directive. Comparison of a Manufacturer's Danish and Norwegian Operations. Sustainability 2020, 12, 5236. [CrossRef]

27. Lawrenz, S.; Nippraschk, M.; Wallat, P.; Rausch, A.; Goldmann, D.; Lohrengel, A. Is it all about Information? The Role of the Information Gap between Stakeholders in the Context of the Circular Economy. Procedia CIRP 2021, 98, 364-369. [CrossRef]

28. Polat, O.; Capraz, O.; Gungor, A. Modelling of WEEE recycling operation planning under uncertainty. J. Clean. Prod. 2018, 180, 769-779. [CrossRef]

29. Krook, J.; Svensson, N.; Eklund, M. Landfill mining: A critical review of two decades of research. Waste Manag. 2012, 32, 513-520. [CrossRef]

30. Zhang, L.; Geng, Y.; Zhong, Y.; Dong, H.; Liu, Z. A bibliometric analysis on waste electrical and electronic equipment research. Environ. Sci. Pollut. Res. 2019, 26, 21098-21108. [CrossRef] 
31. Cesaro, A.; Marra, A.; Kuchta, K.; Belgırno, V.; Van Hullebusch, E.D. WEEE management in a circular economy perspective: An overview. Glob. NEST J. 2018, 20, 743-750.

32. European Commission. Waste Electrical and Electronic Equipment Directive; [WEEE] 2002/96/EC; European Commission: Brussels, Belgium, 2002.

33. European Commission. Directive 2012/19/EU of the European Parliament and of the Council of 4 July 2012 on waste electrical and electronic equipment (WEEE). Off. J. Eur. Union 2012, 197, 38-71.

34. OECD. Extended Producer Responsibility. 2017. Available online: http://www.oecd.org/env/tools-evaluation/extendedproducerresponsibility.htm (accessed on 30 August 2021).

35. Fleckinger, P.; Glachant, M. The organization of extended producer responsibility in waste policy with product differentiation. $J$. Environ. Econ. Manag. 2010, 59, 57-66. [CrossRef]

36. Wang, H.; Gu, Y.; Li, L.; Liu, T.; Wu, Y.; Zuo, T. Operating models and development trends in the extended producer responsibility system for waste electrical and electronic equipment. Resour. Conserv. Recycl. 2017, 127, 159-167. [CrossRef]

37. Cooper, M.C.; Lambert, D.M.; Pagh, J.D. Supply Chain Management: More Than a New Name for Logistics. Int. J. Logist. Manag. 1997, 8, 1. [CrossRef]

38. Daugherty, P.J.; Myers, M.B.; Richey, R.G. Information Support for reverse logistics: The influence of relationship commitment. J. Bus. Logist. 2002, 23, 85-106. [CrossRef]

39. Shi, X.; Li, L.X.; Yang, L.; Li, Z.; Choi, J.Y. Information flow in reverse logistics: An industrial information integration study. Inf. Technol. Manag. 2012, 13, 217-232. [CrossRef]

40. Madenas, N.; Tiwari, A.; Turner, C.J.; Woodward, J. Information flow in supply chain management: A review across the product lifecycle. CIRP J. Manuf. Sci. Technol. 2014, 7, 335-346. [CrossRef]

41. Kurilova-Palisaitiene, J.; Lindkvist, L.; Sundin, E. Towards Facilitating Circular Product Life-Cycle Information Flow via Remanufacturing. Procedia CIRP 2015, 29, 780-785. [CrossRef]

42. ISO. ISO 14001, in Environmental Management Systems-Requirements with Guidance for Use; International Organization for Standardization: Geneva, Switzerland, 2015.

43. Mazzi, A.; Toniolo, S.; Catto, S.; De Lorenzi, V.; Scipioni, A. The combination of an Environmental Management System and Life Cycle Assessment at the territorial level. Environ. Impact Assess. Rev. 2017, 63, 59-71. [CrossRef]

44. Daniels, P.L.; Moore, S. Approaches for Quantifying the Metabolism of Physical Economies: Part I: Methodological Overview. J. Ind. Ecol. 2001, 5, 69-93. [CrossRef]

45. Ahlroth, S.; Nilsson, M.; Finnveden, G.; Hjelm, O.; Hochschorner, E. Weighting and valuation in selected environmental systems analysis tools-Suggestions for further developments. J. Clean. Prod. 2011, 19, 145-156. [CrossRef]

46. Bicalho, T.; Sauer, I.; Rambaud, A.; Altukhova, Y. LCA data quality: A management science perspective. J. Clean. Prod. 2017, 156, 888-898. [CrossRef]

47. Islam, M.T.; Huda, N. Material flow analysis (MFA) as a strategic tool in E-waste management: Applications, trends and future directions. J. Environ. Manag. 2019, 244, 344-361. [CrossRef]

48. Kurniadi, K.A.; Ryu, K. Maintaining Sustainability in Reconfigurable Manufacturing Systems Featuring Green-BOM. Int. J. Precis. Eng. Manuf. Technol. 2020, 7, 755-767. [CrossRef]

49. Bogers, M. The open innovation paradox: Knowledge sharing and protection in R\&D collaborations. Eur. J. Innov. Manag. 2011, 14, 93-117. [CrossRef]

50. Davies, I.; Green, P.F.; Rosemann, M.; Indulska, M.; Gallo, S. How do practitioners use conceptual modeling in practice? Data Knowl. Eng. 2006, 58, 358-380. [CrossRef]

51. Parajuly, K.; Wenzel, H. Product Family Approach in E-Waste Management: A Conceptual Framework for Circular Economy. Sustainability 2017, 9, 768. [CrossRef]

52. Song, X.; Wang, J.; Yang, J.; Lu, B. An updated review and conceptual model for optimizing WEEE management in China from a life cycle perspective. Front. Environ. Sci. Eng. 2017, 11, 3. [CrossRef]

53. Moody, D.L. Theoretical and practical issues in evaluating the quality of conceptual models: Current state and future directions. Data Knowl. Eng. 2005, 55, 243-276. [CrossRef]

54. Norway, G. Guideline for Unique Identification of Products with SGTIN; The Global Language Business: Boston, MA, USA, 2018.

55. Nnorom, I.; Osibanjo, O. Toxicity characterization of waste mobile phone plastics. J. Hazard. Mater. 2009, 161, 183-188. [CrossRef]

56. Goltsos, T.E.; Syntetos, A.A.; Van Der Laan, E. Forecasting for remanufacturing: The effects of serialization. J. Oper. Manag. 2019, 65, 447-467. [CrossRef]

57. Gerbert, P. Industry 4.0-The Future of Productivity and Growth in Manufacturing Industries; The Boston Consulting Group: Boston, MA, USA, 2015.

58. Negri, E.; Fumagalli, L.; Macchi, M. A Review of the Roles of Digital Twin in CPS-based Production Systems. Procedia Manuf. 2017, 11, 939-948. [CrossRef]

59. Bodkhe, U.; Tanwar, S.; Parekh, K.; Khanpara, P.; Tyagi, S.; Kumar, N.; Alazab, M. Blockchain for Industry 4.0: A Comprehensive Review. IEEE Access 2020, 8, 79764-79800. [CrossRef]

60. Kembro, J.; Näslund, D.; Olhager, J. Information sharing across multiple supply chain tiers: A Delphi study on antecedents. Int. J. Prod. Econ. 2017, 193, 77-86. [CrossRef] 
61. Fawcett, S.E.; Osterhaus, P.; Magnan, G.M.; Brau, J.C.; McCarter, M.W. Information sharing and supply chain performance: The role of connectivity and willingness. Supply Chain Manag. Int. J. 2007, 12, 358-368. [CrossRef]

62. Prajogo, D.; Olhager, J. Supply chain integration and performance: The effects of long-term relationships, information technology and sharing, and logistics integration. Int. J. Prod. Econ. 2012, 135, 514-522. [CrossRef]

63. Jannes, K.; Lagaisse, B.; Joosen, W. The Web Browser as Distributed Application Server: Towards Decentralized Web Applications in the Edge. In Proceedings of the 2nd International Workshop on Edge Systems, Analytics and Networking, Dresden, Germany, 25 March 2019; pp. 7-11.

64. Nakamoto, S. Bitcoin: A peer-to-peer electronic cash system. Decentralized Bus. Rev. 2019, 1, 21260.

65. Wang, Y.; Singgih, M.; Wang, J.; Rit, M. Making sense of blockchain technology: How will it transform supply chains? Int. J. Prod. Econ. 2019, 211, 221-236. [CrossRef]

66. Wang, X.V.; Wang, L. WRCloud: A Novel WEEE Remanufacturing Cloud System. Procedia CIRP 2015, 29, 786-791. [CrossRef]

67. Wang, X.V.; Wang, L. Digital twin-based WEEE recycling, recovery and remanufacturing in the background of Industry 4 . Int. J. Prod. Res. 2018, 57, 3892-3902. [CrossRef]

68. Magrini, C.; Nicolas, J.; Berg, H.; Bellini, A.; Paolini, E.; Vincenti, N.; Campadello, L.; Bonoli, A. Using Internet of Things and Distributed Ledger Technology for Digital Circular Economy Enablement: The Case of Electronic Equipment. Sustainability 2021, 13, 4982. [CrossRef]

69. Wang, J.; Wang, S.; Guo, J.; Du, Y.; Cheng, S.; Li, X. A Summary of Research on Blockchain in the Field of Intellectual Property. Procedia Comput. Sci. 2019, 147, 191-197. [CrossRef]

70. Magal, S.; Word, J. Essentials of Business Processes and Information Systems; Wiley Publishing: Hoboken, NJ, USA, 2009.

71. Boccaletti, S.; Bianconi, G.; Criado, R.; del Genio, C.; Gomez-Gardenes, J.; Romance, M.; Sendiña-Nadal, I.; Wang, Z.; Zanin, M. The structure and dynamics of multilayer networks. Phys. Rep. 2014, 544, 1-122. [CrossRef]

72. Bortolini, M.; Galizia, F.G.; Mora, C. Reconfigurable manufacturing systems: Literature review and research trend. J. Manuf. Syst. 2018, 49, 93-106. [CrossRef]

73. European Commission. Statistics for the European Union's (EU) manufacturing sector. In Annual Detailed Enterprise Statistics for Industry; European Commission: Brussels, Belgium, 2015.

74. Klievink, B.; Van Stijn, E.; Hesketh, D.; Aldewereld, H.; Overbeek, S.; Heijmann, F.; Tan, Y.H. Enhancing visibility in international supply chains: The data pipeline concept. Int. J. Electron. Gov. Res. 2012, 8, 14-33. [CrossRef]

75. Sheffi, Y. Balancing Green: When to Embrace Sustainability in a Business (And When Not to); MIT Press: Cambridge, MA, USA, 2018.

76. Gligoric, N.; Krco, S.; Hakola, L.; Vehmas, K.; De, S.; Moessner, K.; Jansson, K.; Polenz, I.; Van Kranenburg, R. SmartTags: IoT Product Passport for Circular Economy Based on Printed Sensors and Unique Item-Level Identifiers. Sensors 2019, 19, 586. [CrossRef]

77. Zhang, Y.; Zhang, P.; Tao, F.; Liu, Y.; Zuo, Y. Consensus aware manufacturing service collaboration optimization under blockchain based Industrial Internet platform. Comput. Ind. Eng. 2019, 135, 1025-1035. [CrossRef]

78. Wang, L.; Wang, X.V.; Gao, L.; Váncza, J. A cloud-based approach for WEEE remanufacturing. CIRP Ann. 2014, 63, 409-412. [CrossRef]

79. Lu, R.; Li, X.; Liang, X.; Shen, X.; Lin, X. GRS: The green, reliability, and security of emerging machine to machine communications. IEEE Commun. Mag. 2011, 49, 28-35. [CrossRef]

80. Damianou, A.; Angelopoulos, C.M.; Katos, V. An Architecture for Blockchain over Edge-enabled IoT for Smart Circular Cities. In Proceedings of the 15th International Conference on Distributed Computing in Sensor Systems (DCOSS), Santorini Island, Greece, 29-31 May 2019; pp. 465-472.

81. Demestichas, K.; Daskalakis, E. Information and Communication Technology Solutions for the Circular Economy. Sustainability 2020, 12, 7272. [CrossRef] 